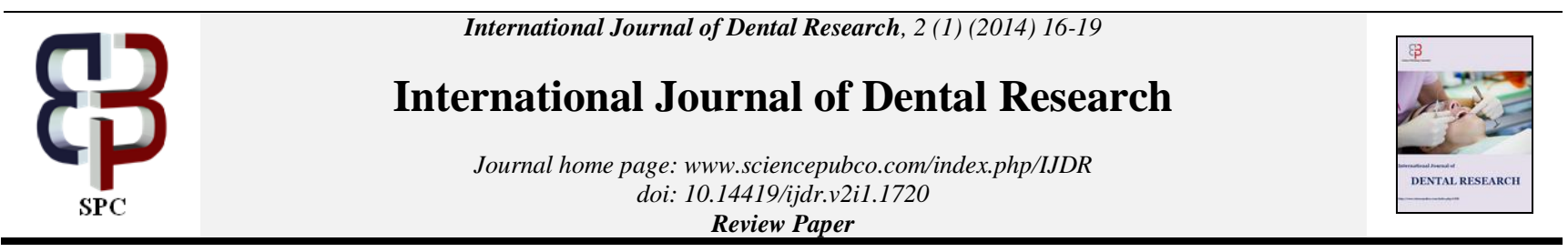

\title{
Soft tissue applications of lasers: A review
}

\author{
Rajat Bhandari ${ }^{1}$, Kartesh Singla ${ }^{1 *}$, Simarpreet Virk Sandhu ${ }^{1}$, Aditya Malhotra ${ }^{2}$, \\ Harmandeep Kaur ${ }^{1}$, Arshdeep Kaur Pannu ${ }^{2}$ \\ ${ }^{1}$ Genesis Institute of Dental Sciences \& Research, Ferozepur, India \\ ${ }^{2}$ Punjab Government Dental College \& Hospital, Amritsar, India \\ *Corresponding author E-mail: singlakartesh@gmail.com
}

\begin{abstract}
Lasers are widely used in dentistry for various clinical procedures like cavity preparation, surgical procedures, scaling and root planning etc. Since its first use in 1960, lasers are now evolved to be used in all aspects of dentistry. The aim of this review is to describe the application of lasers in oral soft tissue procedures. Soft tissue lasers are becoming popular among the clinicians due to their potential value in surgical procedures providing surface sterilization, dry surgical field and increased patient acceptance. Lasers are effective in ablation of various potentially malignant disorders, obtaining biopsy, periodontal plastic surgeries and providing incisions in surgical conditions.
\end{abstract}

Keywords: ablation, biopsy, $\mathrm{CO}_{2}$ laser, cyst, fibroma, gingival, periodontal.

\section{Introduction}

Lasers have been used in medicine and dentistry since early 1960s (Husein 2006). Laser, an acronym for light amplification by stimulated emission of radiation, is a device for generating a highintensity, ostensibly parallel beam of monochromatic electromagnetic radiation (Fuller 1997). This innovative technology works on the principle of stimulated emission theory which was proposed by Einstein in 1917 based on the concept of spontaneous emission theory which was postulated by Neil Bohr in early 1900s. Based on these concepts Maiman developed the first laser prototype in 1960 using ruby crystals as an active medium. The first experiment with lasers in dentistry was reported in a study about the effects of a pulsed ruby laser on human caries (Husein 2006). Several laser systems, such as the diode, ruby, Ho:YAG, Er:YAG, Nd:YAG, and yellow light lasers, as well as dye lasers for photodynamic therapy, have been used for treating various diseases (Werner et al. 2009). With the recent advances and developments of wide range of laser wavelengths and different delivery systems, lasers could be applied for the dental treatments including periodontal, restorative and surgical treatments (Lee 2007). The aim of this review is to describe the soft tissue applications of lasers in dentistry.

There are several types of lasers used in dentistry depending on their wavelength range and their absorption by biological chromophores, e.g., water, hemoglobin, melanin etc. $\mathrm{CO}_{2}$, Er-YAG lasers are absorbed by water, resulting in a minimal penetration depth and fast heating, with effective removal of soft and hard tissue. $\mathrm{CO}_{2}$ lasers are mainly used as laser scalpels for the excision of tumors from soft tissues and in a defocused mode used for superficial tissue vaporization, to treat precancerous lesions in the oral cavity (Neukman, Stelzle 2010). There are several advantages and disadvantages associated with the application of lasers.

\subsection{Advantages (Naik 2010, Mahajan 2011)}

$\bullet$

- Increased patient acceptance.

- Minimal mechanical trauma.

- Negotiates folds in tissues.

\subsection{Disadvantages (Coluzzi \& Swick)}

- $\quad$ They are relatively high in cost.

- $\quad$ Operations of lasers require specialized training.

- Dental instruments mainly used are both side and end cutting thus; a modification of clinical technique is required.

- No single wavelength will optimally treat all dental disease.

- $\quad$ There is inability to remove metallic and cast-porcelain defective restorations by erbium family lasers.

- Harmful to eyes and skin.

\section{Applications of lasers}

Lasers are widely used in dentistry for cavity and root canal preparations, scaling and root planing, gingival and periodontal surgeries, coagulation and hemostasis, biopsies, excision of tongue lesions, TMJ disorders, exposure of implants and preprosthetic surgery. 
Table 1: Different Types of Lasers used in dentistry

\begin{tabular}{|c|c|c|}
\hline Laser & Wavelength & Indications \\
\hline Argon & $\begin{array}{l}488 \mathrm{~nm}, 514 \\
\mathrm{~nm}\end{array}$ & $\begin{array}{l}\text { Pigmented lesions, Vascular anom- } \\
\text { alies, Plastic surgery }\end{array}$ \\
\hline Diode & $620-900 \mathrm{~nm}$ & $\begin{array}{l}\text { Periodontal surgery, Bleaching, } \\
\text { Photodynamic therapy, Soft laser } \\
\text { therapy, Other soft tissue proce- } \\
\text { dures }\end{array}$ \\
\hline $\mathrm{CO}_{2}$ & $10,600 \mathrm{~nm}$ & Soft tissue procedures \\
\hline Nd:YAG & $1,064 \mathrm{~nm}$ & $\begin{array}{l}\text { Soft tissue procedures, Periodontal } \\
\text { surgery, Pigmented lesions }\end{array}$ \\
\hline Ho:YAG & $2,100 \mathrm{~nm}$ & $\begin{array}{l}\text { Arthroscopic surgery, soft tissue } \\
\text { surgery }\end{array}$ \\
\hline Er,Cr:YSGG & 27Ba nm & $\begin{array}{l}\text { Bone surgery, Periodontal surgery, } \\
\text { Cavity preparations }\end{array}$ \\
\hline Er:YAG & $2944 \mathrm{~nm}$ & $\begin{array}{l}\text { Bone-surgery, Skin resurfacing, } \\
\text { Cavity preparations }\end{array}$ \\
\hline
\end{tabular}

\section{Soft tissue application of lasers in dentistry}

\subsection{Applications in oral surgery}

$\begin{array}{ll}\text { - } & \text { Hemostasis. } \\ \text { - } & \text { Malformations. } \\ \text { - } & \text { Preprosthetic surgeries. } \\ \text { - } & \text { Precancerous lesions. } \\ \text { - } & \text { Benign tumors. } \\ \text { - } & \text { Scar corrections. } \\ \text { - } & \text { Low Level Laser Therapy. }\end{array}$

\subsection{Applications in periodontics}

$\begin{array}{ll}\text { - } & \text { Gingivectomy. } \\ \text { - } & \text { Frenectomy. } \\ \text { - } & \text { Removal of granulation tissue. } \\ \text { - } & \text { Removal of melanin pigmentation and metal tattoos. } \\ \text { - } & \text { Osseous recontouring as well as in implant surgery. } \\ \text { - } & \text { Maintenance of implants. } \\ \text { Low Level Laser Therapy. }\end{array}$

\subsection{Applications in orthodontics}

- $\quad$ Aesthetic gingival recontouring.

- Soft tissue crown lengthening.

- Exposure of soft-tissue impacted teet.h.

- Removal of inflamed and hypertrophic tissue.

- Frenectomy.

- $\quad$ Tissue removal at the site for mini screw.

- Low Level Laser Therapy.

\subsection{Applications in conservative dentistry \& endodon-} tics

- $\quad$ Dentinal Hypersensitivity.

- $\quad$ Pulp Capping \& Pulpotomy.

- $\quad$ Cleaning of root canals.

- Sterilization of the root canals.

\subsection{Diagnosis of lesions}

\subsection{Low level laser therapy}

\subsection{Applications in oral surgery}

Laser can be a useful treatment modality for obtaining biopsy specimens without tissue destruction. Luomanen M et al. Suggested that use of $\mathrm{CO}_{2}$ laser leads to a level of precision similar to and sometimes better than that of scalpel in the treatment of benign oral soft tissue lesions (Luomanen 1992).

a) Peripheral Ossifying Fibromas occurs solely on the soft tis-sue overlying the alveolar process. It is a common gingival growth that usually arises from the interdental papilla. The etiopathogenesis of peripheral ossifying fibroma is unclear but trauma or local irritation due to dental plaque, calculus, ill-fitting dental appliances and poor-quality dental restorations can lead to the development. These lesions can be effectively treated with Er,Cr:YSGG. Iyer VH et al. reported that the outcome was painless experience to the patient, minimal intraoperative bleeding in the surgical field and excellent healing of the operated area in 1 week period (Iyer et al. 2012)

b) Denture-induced fibrous hyperplasia is a response of tissues to a chronically ill- fitting denture and present as a benign condition which frequently coexists with denture stomatitis. Kumar NJ et al. successfully treated the case of denture in-duced fibrous hyperplasia with the help of carbon dioxide laser and concluded that $\mathrm{CO}_{2}$ lasers could be an excellent alternative to conventional modalities (Kumar, Bhaskaran 2007)

c) Mucoceles are benign lesions of the oral cavity that develop due to extravasation or retention of mucous from salivary glands in the subepithelial tissue generally in response to trauma. Pedron IJ et al. on the basis of findings of their study concluded that laser treatment provides satisfactory results and allowed for a satisfactory histopathological examination of the excised tissue in case of mucocele (Pedron et al. 2010)

d) Hemangiomas are benign vascular proliferations consisting of numerous capillary structures usually present on the tongue, lips, mucous membrane and gingiva. Genovese WJ et al concluded that application of gallium arsenide (GaAs) high potency diode laser in the treatment of hemangionma reduced bleeding during surgery, with a consequent reduction in operating time and promoted rapid postoperative hemostasis (Genovese et al 2010) Apfelberg DB et al recommended the laser treatment for excisional surgery of hemangioma (Apfelberg et al. 1985)

e) Lymphangioma is often asymptomatic and is detected with the appearance of a slow growing painless cystic mass covered by healthy mucosa. Despite being a congenital benign lesion, lymphangioma may cause severe esthetic deformities, and surgical excision is the main treatment. Dos Santos Aciole GT et al reported that the use of $\mathrm{CO}_{2}$ laser was practical, easy to carry out and effective on the treatment of oral lymphangiomas, with no lesion recurrence within the follow-up periods (dos Santos Aciole et al. 2010)

f) In Suspected dysplastic or neoplastic lesions (e.g., leukoplakia, lichen planus, cancer, melanoma, etc), even with little peripheral laser thermal effect it is prudent to enlarge the surgical incision, at least to around $0.5 \mathrm{~mm}$ in circumference, in order to make a histological diagnosis free from doubt or uncertainty (Romeo et al. 2007) Flynn FB reported that vaporization of the dysplastic lesions with carbon dioxide laser is recommended for patients with an identifiable risk for the development of intraoral malignancy. This is an effective, non-morbid, inexpensive, quick, and relatively painless method of managing this condition (Flynn et al. 1988) Laser resection/ablation is recommended for oral dysplasia to prevent not only recurrence and malignant transformation but also postoperative oral dysfunction encountered by other conventional modalities (Jerjes et al. 2012) In leukoplakia or hyperkeratotic lesions cryotherapy ablation and $\mathrm{CO}_{2}$ laser is used and the operated area heals rapidly (Gaeta 2013). van der Hem PS et al concluded on the basis of results of their study that laser treatment is a good prophylactic treatment for oral leukoplakia (van der Hem et al. 2005) Kok \& Ong assessed the effectiveness of $\mathrm{CO}_{2}$ laser in relieving symptoms associated with oral lichen planus and lichenoid lesions and the event of healing. They concluded that the 
use of $\mathrm{CO}_{2}$ laser in the treatment of oral lichen planus and lichenoid reaction shows positive results in relieving symptoms associated with these lesions (Kok \& Ong 2001)

g) Treatment of infectious lesions: Erbium laser may be used for ablation or decontamination of infective lesions. Lasers are used in treatment of herpetic lesions, candidiasis lesions, and papilloma virus lesions (Gaeta 2013).

h) Dentigerous cysts are benign odontogenic cysts associated with the crown of an unerupted tooth. They can expand the cortical bone to such an extent that they cause displacement of teeth and root resorption in the adjacent teeth. Boj JR treated a case of dentigerous cyst by preparation of mucous fenestration using an erbium laser followed by drainage of the fluid content and curettage and the injury was success-fully resolved (Boj et al. 2007).

i) Cancer: Lasers as surgical tools have an important role in the diagnosis and treatment of cancer. The $\mathrm{CO}_{2}$ laser currently has the greatest significance in otorhinolaryngology, predominantly in the treatment of carcinomas of the upper aerodigestive tract (LópezÁlvarez et al. 2011) The neoplastic cells can be removed either by hyperthermic (cells are destroyed by laser heat or photodynamic combination of special photosensitive drug with specific type of laser) methods (National Cancer Institute 2011).

\subsection{Applications in periodontics}

Laser is a viable alternative to the scalpel for various soft tissue procedures such as frenectomy, gingivectomy and gingivoplasty, de-epithelization of reflected periodontal flaps, removal of granulation tissue and crown lengthening.

a) Gingivectomy: The removal of gingival tissue for restorative purposes is usually performed in order for a clinician to gain access and deliver treatment to areas located below the gingival margin and for the treatment of gingival hyperplasia. Alternatives for gingival tissue removal include the use of a scalpel, electrosurgery, and/or lasers. Lasers offer the potential of increased operator control and minimal collateral tissue damage. Diode lasers specifically, operate at a wavelength that is easily absorbed by the gingival tissues, while posing little risk of damaging the tooth structure. [25] Pick RM et al presented a 12 cases of phenytoin hyperplasia removed surgically by the $\mathrm{CO} 2$ lasers and hence laser gin-givectomy and suggested that in the future the laser may offer an alternative or an advancement to current procedures now used in dentistry (Pick et al. 1985)

b) Crown Lengthening: Lasers have been promoted for clinical crown lengthening without gingival flap reflection for both esthetic and prosthetic reasons. However, currently there are no controlled longitudinal or cohort studies supporting the use of lasers for clinical crown lengthening using the closed- flap technique. The only existing supports for such applications are non- controlled case reports (Cobb 2006).

c) Frenectomy: Laser surgery may be considered a useful tool for the clinician in performing frenectomy. According to Kafas $\mathrm{P}$ et al. diode laser frenectomy may be performed without infiltrated anaesthesia with the optimum healing postsurgically (Kafas et al. 2009)

d) Tissue Pigmentation Reduction: Recently, laser has been widely used and is even preferred over the scalpel technique procedures for depigmentation (Roshna \& Nandakumar 2005).

\subsection{Applications in orthodontics}

Lasers are widely used in Orthodontics for aesthetic gingival recontouring, soft tissue crown lengthening, exposure of soft-tissue over the impacted teeth, removal of inflamed and hypertrophic tissue, frenectomy in case of highly attached frenum causing hindrance to tooth movement in diastema cases, tissue removal at the site for mini screw and Low Level Laser Therapy for reduction in pain experienced during the orthodontic therapy.
Soft tissue lasers have been successfully used for the removal of coronal pulp and immediate pulp capping due its thermal and hemostatic effect. Lasers causes modification of the tubular structure of dentin by melting and fusing of the hard tissue or smear layer and subsequent sealing of dentinal tubules leading to reduction in sensitivity of teeth. Laser radiation has the ability to remove debris and smear layer from the root canals due to its potential to kill the microorganisms by its thermal effects.

\subsection{Diagnosis of lesions}

Laser capture microdissection (LCM) greatly improved the efforts in describing the molecular basis of malignancy. In early 1970s primitive UV laser was first used by Isenberg et al. but their approach required massive space occupying instruments to dissect subpopulations of cell types. The first commercialized system was devised by Lance Liotta, Emmert-Buck and co-workers in mid 1990s for accurately and efficiently dissection of cells from histological tissue sections of solid tumors (Domazet et al. 2008) LCM provides an ideal method for the extraction of cells from specimens in which the exact morphology of both the captured cells and the surrounding tissue are preserved. When LCM is combined with immunohistochemical staining techniques, more accurate microdissection of cellular subsets can be obtained. This technique variably helps in early detection of oral squamous cell carcinoma by detecting the biomarkers and establishing protein fingerprint models (Mehrotra \& Gupta 2011).

\subsection{Low level laser therapy}

Low level laser therapy (LLLT) is defined as laser treatment in which the energy output is low enough to produce nonthermal and biostimulatory effects. The mechanisms of effect of LLLT causing laser analgesia are due to the stabilization of depolarising potential of nerve fibres or effects on the cellular and biochemical processes of the inflammatory responses. It is a new treatment modality and has the advantages of being painless with no side effects. LLLT has effectively used in pain during orthodontic therapy, acceleration of healing process in wound, reduction of bacterial load in ulcerative conditions like apthous ulcer, infections etc. (HongMeng et al. 1995)

\section{Effects of laser on soft tissues}

Laser can lead to warming, welding, coagulation, protein denaturation, drying, vaporization and carbonization causing the histological changes such as intracellular vacuolization, cellular hyperchromatism and loss of intracellular structure, with the degree of charring of the tissues. Epithelial changes like blisters, clefts, erosions, and any intraepithelial or subepithelial loss of attachment and vascular changes like intraluminal clotted erythrocytes, vascular stasis with presence of gathered erythrocytes and thrombosed or collapsed blood or lymphatic vessels can also occur. If diseasefree margins are needed, the pathologist could encounter serious difficulties to evaluate them due to the presence of charred tissue, artifacts and denaturalised, coagulated and disorganized tissue of variable extension around the margins (Kende et al. 2011)

\section{Conclusion}

The application of lasers has been recognized as an adjunctive or alternative approach in soft tissue surgeries. Laser treatments have been shown to be superior to conventional mechanical approaches with regard to easy ablation, decontamination and hemostasis, as well as less surgical and postoperative pain in soft tissue management. 
Table 2: Histological alterations seen in laser treated tissues

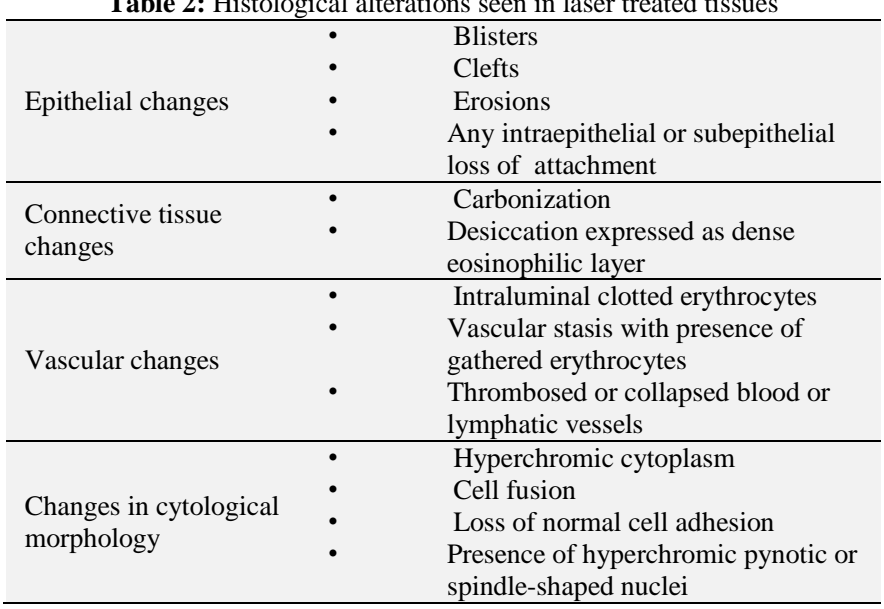

\section{References}

[1] Apfelberg DB, Maser MR, Lash H \& White DN (1985) Benefits of the $\mathrm{CO}_{2}$ laser in oral hemangioma excision. Plastic and Reconstructive Surgery 75, 46-50.

[2] Boj JR, Poirier C, Hernandez M \& Espasa E (2007) Laser-assisted treatment of a dentigerous cyst: case report. Pediatric dentistry 29, 521-4.

[3] Cobb CM (2006) Lasers in periodontics: a review of the literature. The Journal of Periodontology. 77, 545-64.

[4] Coluzzi DJ \& Swick MD http://www.henryschein. com/usen/images/Dental/CEHP/LaserinDentistry.pdf (accessed 14 March 2013)

[5] dos Santos Aciole GT, dos Santos Aciole JM, Soares LJP, Santos NRS, dos Santos JN \& Pinheiro ALB (2010) Surgical Treatment of Oral Lymphangiomas with $\mathrm{CO}_{2}$ Laser: Report of Two Uncommon Cases. Brazilian Dental Journal 21,365-9.

[6] Domazet B, Maclennan GT, Lopez-Beltran A, Montironi R \& Cheng L (2008) Laser capture microdissection in the genomic and proteomic era: targeting the genetic basis of cancer. International Journal of Clinical and Experimental Pathology 1, 475-88.

[7] Flynn MB, White M \& Tabah RJ (1988) Use of carbon dioxide laser for the treatment of premalignant lesions of the oral mucosa. Journal of Surgical Oncology 37,232-4.

[8] Fuller TA (1997) Physical Considerations of Surgical Lasers. (Clayman L, Kuo P eds.) Lasers in Maxillofacial Surgery and Dentistry, 1st ed. United States of America: Thieme.

[9] Gaeta GM (2013) Laser Treatment in Medicine and Oral Pathology. http://www.giovannimariagaeta.it/Laser\%20Book\%202010.pdf (accessed 17 January 2013).

[10]Genovese WJ, dos Santos MT, Faloppa F \& de Souza Merli LA (2010) the use of surgical diode laser in oral hemangioma: a case report. Photomedicine and Laser Surgery 28,147-51.

[11]Hong-Meng L, Kenneth KKL \& David KLT (1995) A clinical investigation of the efficacy of low level laser therapy in reducing orthodontic postadjustment pain. American Journal of Orthodontics and Dentofacial Orthopedics 108, 614-22.

[12]Husein A (2006) Applications of lasers in dentistry: a review. Archives of Orofacial Sciences 1, 1-4.

[13]Iyer VH, Sarkar S \& Kailasam S (2012) Use of the Er,Cr:YSGG Laser in the Treatment of Peripheral Ossifying Fibroma. International Journal of Laser Dentistry 2, 51-55.

[14]Jerjes W, Upile T, Hamdoon Z, Al-Khawalde M, Morcos M, Mosse CA \& Hopper C (2012) CO2 laser of oral dysplasia: clinicopathological features of recurrence and malignant transformation. Lasers in Medical Science 27,169-79.

[15]Kafas P, Stavrianos C, Jerjes W, Upile T, Vourvachis M, Theodoridis M \& Stavrianou I (2009) Upper-lip laser frenectomy without infiltrated anaesthesia in a paediatric patient: a case report. Cases Journal 2, 7138.

[16]Kende P, Gaikwad R, Yuwanati M \& Jain B (2011) Application of Diode Laser in Oral Biopsy: Removal of White Patch Over Tongue A Case Report. Journal of Indian Dental Association 5, 985-7.

[17]Kok TC \& Ong ST (2001) the effects of $\mathrm{CO}_{2}$ lasers on oral lichen planus and lichenoid reactions. Annals of Dentistry University of $\mathrm{Ma}$ laya $8,35-42$.

[18]Kumar NJ \& Bhaskaran M (2007) Denture-induced fibrous hyperplasia:treatment with carbon dioxide laser and a two year follow-up. Indian Journal of Dental Research 18, 135-7e.
[19]Lee DH (2007) Application of lasers in periodontics: a new approach in periodontal treatment. Dental Bulletin 12, 23-5.

[20]Lee EA (2006) Laser-assisted gingival tissue procedures in esthetic dentistry. Practical Procedures and Aesthetic Dentistry 18, suppl 2-6.

[21]López-Álvarez F, Rodrigo JP, Llorente-Pendás JL \& Suárez-Nieto C (2011) Transoral laser microsurgery in advanced carcinomas of larynx and pharynx. Acta Otorrinolaringológica Española 62, 95-102.

[22]Luomanen M (1992) Experience with a carbon dioxide laser for removal of benign oral soft-tissue lesions. Proceedings of the Finnish Dental Society 88, 49-55.

[23] Mahajan A (2011) Lasers in periodontics: a review. European Journal of Dentistry and Medicine. 3, 1-11.

[24] Mehrotra R \& Gupta DK (2011) Exciting new advances in oral cancer diagnosis: avenues to early detection. Head \& Neck Oncoogy 28, 33.

[25]Naik VK, Sangeetha S \& Victor DJ (2010) Lasers in periodonticsascientific boon or bane? SRM University Journal of Dental Sciences $1,91-8$.

[26] National Cancer Institute (2011) Lasers in Cancer Treatment, Available at: http://www.cancer.gov/cancertopics/factsheet/Therapy/ lasers (Accessed: 20th January 2013).

[27]Neukman FW \& Stelzle F (2010) Laser tumor treatment in oral and maxillofacial surgery. Physics Procedia 5, 91-100.

[28]Pedron IG, Galletta VC, Azevedo LH \& Corrêa L (2010) Treatment of mucocele of the lower lip with diode laser in pediatric patients: presentation of 2 clinical cases. Pediatric Dentistry 32,539-41.

[29]Pick RM, Pecaro BC \& Silberman CJ (1985) the laser gingivectomy: the use of $\mathrm{CO} 2$ laser for the removal of phenytoin hyperplasia. The Journal of Periodontology 56, 492-6.

[30]Romeo U, Vecchiob AD, Riparic F, Palaiad G, Chiappafreddoe C, Tenored G \& Visca P (2007) Effects of Different Laser Devices on Oral Soft Tissues: In Vitro Experience. J Oral Laser Applications 7,155-159.

[31]Roshna T \& Nandakumar K (2005) Anterior Esthetic Gingival Depigmentation and Crown Lengthening: Report of a Case. The Journal of Contemporary Dental Practice 15,139-147.

[32] Van der Hem PS, Nauta JM, van der Wal JE \& Roodenburg JL (2005) the results of $\mathrm{CO}_{2}$ laser surgery in patients with oral leukoplakia: a 25 year follow up. Oral Oncology 41, 31-7.

[33]Werner JA, Dunne AA, Folj BJ \& Lippert BM (2009) Transoral laser microsurgery in carcinomas of the oral cavity, pharynx, and larynx. Cancer Control 9, 379-88. 